\title{
ИННОВАЦИОННОЕ РАЗВИТИЕ АВТОМОБИЛЬНОГО КЛАСТЕРА КАК ФАКТОР ОБЕСПЕЧЕНИЯ КОНКУРЕНТОСПОСОБНОСТИ АВТОМОБИЛЬНЫХ ПРЕДПРИЯТИЙ
}

\section{INNOVATIVE DEVELOPMENT \\ OF THE AUTOMOBILE CLUSTER \\ AS A FACTOR OF ENSURING \\ THE COMPETITIVENESS \\ OF AUTOMOBILE ENTERPRISES}

Yu. Mindlin

Summary. In this article, a theoretical study of scientific approaches to determining the content of the concept of "cluster", determinants and forms of clustering of the economy was conducted. The critical analysis allowed to form an improved definition of the concept of a cluster as a system of interconnected vertical and horizontal connections of business entities (service and communication and transport infrastructure enterprises, financial institutions, research institutions and management bodies), which have different degrees of legal independence, specialization, geographical concentration and operate on the principles of division of labor, innovation and technological orientation and cooperation, this allows them to receive additional socio-economic benefits. The automobile cluster is analyzed on the example of the Kaluga region as the most effective among other Russian automobile clusters.

Keywords: cluster, competitiveness, automotive industry, development, partnership, structure.

\section{Особенности конкуренции в двтомобилестроении}

Неотъемлемой и стратегически важной частью машиностроения, промышленности и национальной экономики в целом является автомобилестроение.

Автомобилестроение (автомобильная промышленность) - это область транспортного машиностроения, производящая моторизованные нерельсовые транспортные средства, в частности, легковые автомобили, грузовые автомобили и автобусы [1].

Производство автомобилей обеспечивает высокий показатель добавленной стоимости (более 70\%), формирует спрос на товары и услуги предприятий смежных отраслей (производство металлопроката, пластмасс, автостекла, автохимии т. д) и стимулирует научно-исследовательскую деятельность. Создание одного рабочего

\author{
Миндлин Юрий Борисович \\ К.э.н., дочент, ФГБОУ ВО «Московская \\ государственная академия ветеринарной медицины \\ и биотехнологии имени К. И. Скрябина» \\ mindliny@mail.ru
}

Аннотация. В данной статье было проведено теоретическое исследование научных подходов к определению содержания понятия «кластер», детерминант и форм кластеризации экономики. Проведеный критический анализ позволил сформировать усовершенствованное определение понятия кластера как системы взаимосвязанных вертикальными и горизонтальными связями субъектов хозяйствования (предприятия сервисной и коммуникационно-транспортной инфраструктуры, финансовые учреждения, научно-исследовательские учреждения и органы управления), которые имеют разную степень юридической самостоятельности, специализации, географической концентрации и функционируют на принципах разделения труда, инновационно-технологической направленности и кооперирования, что позволяет им получать дополнительные социально-экономические выгоды. Проанализирован автомобильный кластер на примере Калужской области как наиболее эффективный среди прочих российских автомобильных кластеров.

Ключевые слова: кластер, конкурентоспособность, автомобильная отрасль, развитие, партнерство, структура.

места на предприятиях автомобилестроительной отрасли вызывает создание не менее шести рабочих мест в смежных отраслях [2].

Производство автотранспортных средств как часть машиностроительного комплекс относится к перечню приоритетных отраслей экономики. Учитывая то, что конкурентоспособность предприятия определяется конкурентоспособностью продукции и конкурентным потенциалом, следует предоставить дефиниции сущности указанных экономических категорий в контексте исследование развития автомобильной промышленности.

Так, предлагаем под конкурентоспособностью продукции предприятия автомобилестроения понимать динамическое свойство автомобилестроительной продукции на определенном этапе жизненного цикла получать конкурентные преимущества по ценовым и неценовыми 
характеристиками по сравнению с аналогичной автомобилестроительной продукцией на рынке автомобилей в результате взаимодействия конкурентного потенциала автопроизводителя и факторов внешней среды, сопровождающейся получением экономического, социального и/или других эффектов в соответствии с конкурентной стратегии.

Соответственно, конкурентный потенциал предприятия автомобилестроения - это совокупность реализованных и потенциальных производственных, кадровых, управленческих, инновационно-инвестиционных, финансовых, стратегических и рыночных ресурсов автопроизводителя, обеспечивающих конкурентоспособность автомобилестроительной продукции на рынке автомобилей и эффективность всех видов деятельности автомобилестроительного предприятия на разных этапах его жизненного цикла.

С учетом вышеупомянутого, под конкурентоспособностью предприятия автомобилестроения предлагаем понимать динамическое свойство автомобилестроительного предприятия по обеспечению конкурентоспособности автомобилестроительной продукции на рынке автомобилей, эффективности всех видов деятельности в результате взаимодействия конкурентного потенциала и факторов внешней среды в соответствии с выбранной конкурентной стратегии на определенном этапе жизненного цикла.

В данной дефиниции, в отличие от имеющихся, одновременно указывается на следующее [3]:

- конкурентоспособность предприятия является динамичной, а не статичной;

- конкурентоспособность является не возможностью, способностью, характеристикой предприятия, а его неотъемлемым свойством, присущим ему с момента создания до момента ликвидации - на всех этапах жизненного цикла;

- конкурентоспособность предприятия формируется в результате взаимодействия конкурентного потенциала предприятия и факторов внешней (в том числе конкурентной рыночной) среды;

- обязательным условием достижения конкурентного состояния субъектом хозяйствования является эффективность всех видов деятельности в соответствии с стратегических целей, которые ставятся руководством предприятия на определенных этапах жизненного цикла.

В контексте позиционирования конкурентоспособности предприятий автомобилестроительного комплекса как основного идентификационного признака развития автомобильной промышленности предлагаем сферическую модель развития автомо- билестроения в условиях осложнения конкурентной среды [4].

На рис. 1 сферическая модель развития автомобилестроения в условиях осложнения конкурентной среды представлена в упрощенном виде (на примере 2-х участников рынка) и состоит из четырех подрядных сфер: «внешняя среда», «конкурентная рыночная среда», «конкурентный потенциал», «конкурентоспособность продукции».

Первой сферой является внешняя среда, факторы которой осуществляют влияние, как на формирование конкурентной рыночной среды, так и на формирование конкурентоспособности продукции, конкурентного потенциала конкурентоспособности предприятий. Влияние факторов внешней среды подвергается первичной и вторичной трансформации - при взаимодействии с конкурентной рыночной средой и конкурентным потенциалом. Трансформация происходит и с воздействием на процесс формирования конкурентоспособности предприятий факторов конкурентного рыночной среды при взаимодействии с конкурентным потенциалом предприятий.

Следующей особенностью сферической модели развития автомобилестроения является выделение зон первичной и вторичной конкуренции. Так, первичная конкуренция имеет место при конкурентном взаимодействии в рыночной среде продукции предприятий. Впрочем, на практике предприятия конкурируют не только посредством продукции - происходит взаимодействие конкурентных потенциалов производителей и формирование зоны вторичной конкуренции.

Предложенная сферическая модель развития автомобилестроения в условиях осложнения конкурентной среды: предполагает трансформацию влияния факторов внешней среды на формирование конкурентоспособности автопроизводителей при взаимодействии с конкурентным рыночной средой и конкурентным потенциалом, а также трансформацию факторов конкурентной рыночной среды при взаимодействии с конкурентным потенциалом автомобилестроительных предприятий; предлагает идентификацию действующего уровня конкурентоспособности автопроизводителей через их двухэтапную взаимодействие в зонах первичной и вторичной конкуренции.

Сегодня для поддержки конкурентоспособности и своего конкурентного потенциала многие ведущие компании вступают в новую фазу своего развития объединяются в кластеры с инновационными и научными организациями. Эффективность такого сотрудничества возрастает в разы, а при постоянно изменчивой 

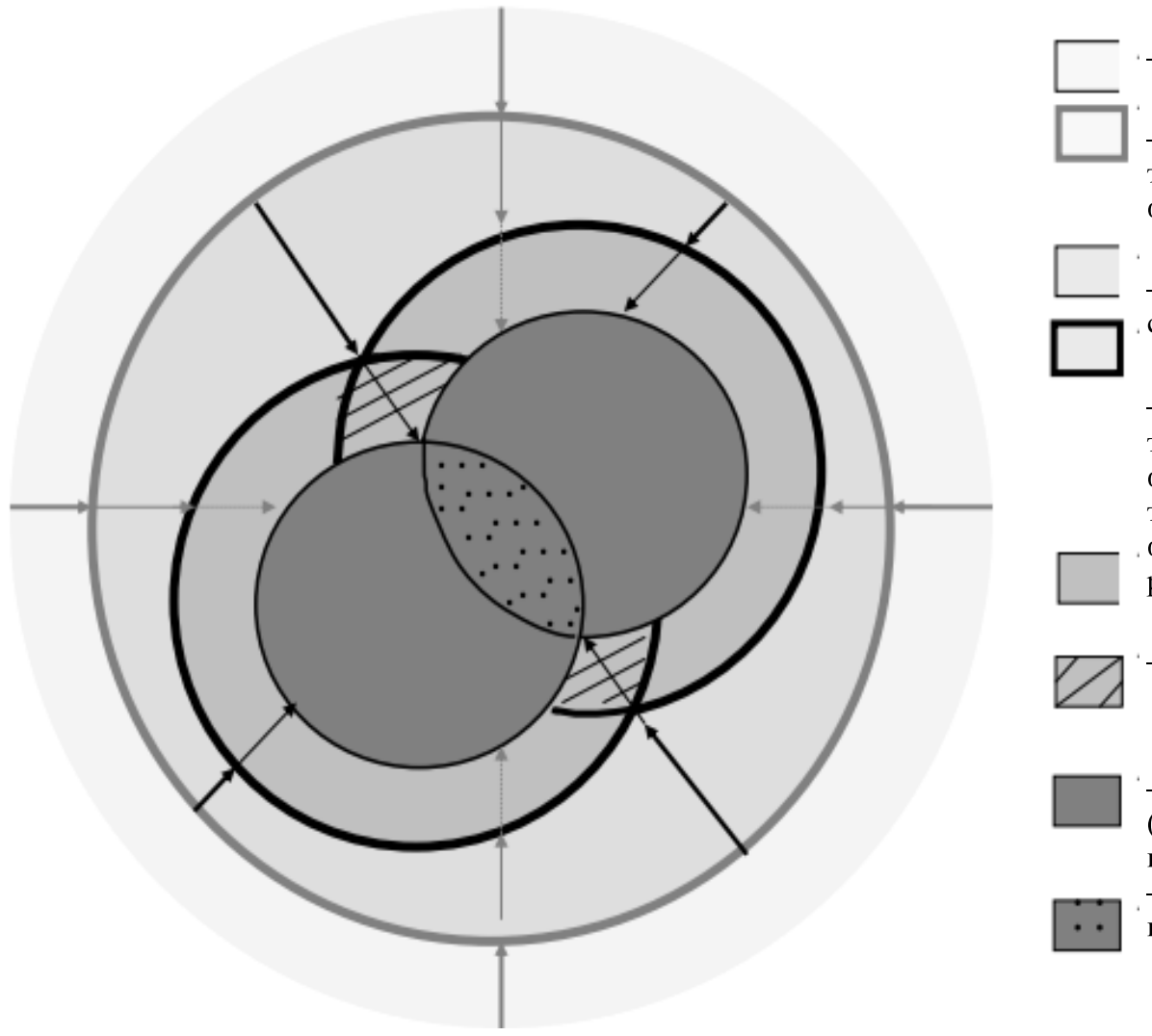

- внешняя среда

- зона первичной

трансформации влияния факторов внешней среды

- конкурентная рыночная

среда

- зона вторичной

трансформации влияния факторов внешней среды и трансформации влияния факторов конкурентного рыночной среды

- конкурентный потенциал

Рис. 1. Сферическая модель развития автомобилестроения в условиях осложнения конкурентной среды (на примере 2-х участников автомобильного рынка)

Источник: составлено автором

внешней среде, только консолидация ресурсов и позволит устоять в современных реалиях.

\section{Кластеризашия: сохранение конкурентного потеншиала и $\triangle$ ОСТУП К ИнНОВациям}

Кластеры являются отражением содержания экономических образований субъектов хозяйствования, которые в XXI веке развиваются под влиянием современных цивилизационных парадигм постиндустриального общества. Развитие информационных технологий и коммуникаций коренным образом изменил принципы функционирования кластерных структур в современном мире. Инновационный кластер - это система взаимосвязанных вертикальными и горизонтальными связями субъектов хозяйствования (включая производственные предприятия, научно-исследовательские институты, предприятия сервисной и коммуникационно-транспортной инфраструктуры, финансовые учреждения, научно-образовательные учреждения и органы управления), которые имеют разную степень юридической самостоятельности, специализации, географической концентрации и функционируют на основе разделения труда, инновационно-технологической направленности и кооперирование, что позволяет им получать дополнительные социально-экономические выгоды.

Основными признаками, по которым предприятия и организации объединяются в промышленный кластер являются следующие: родство продукции или принадлежность к одной отрасли; наличие и необходимость дальнейшего развития процессов кооперации; нахождение на одной территории; необходимость технологической и технической переоснастки производства, доступа к современным инновациям и технологиям; рост производственных мощностей и их концентрации, что требуют активизации и систематизации процессов поставки сырья и сбыта продукции; желание выйти совместным усилиями на внешние экономические рынки; рост специализации производства и другие.

Основываясь на вышеизложенном, следует отметить, что основными детерминантами формирования кластеров является рост гибкости работы предприятий в рамках кластерной системы, а также достижения экономии 


\section{Классификация форм кластеризации экономики}

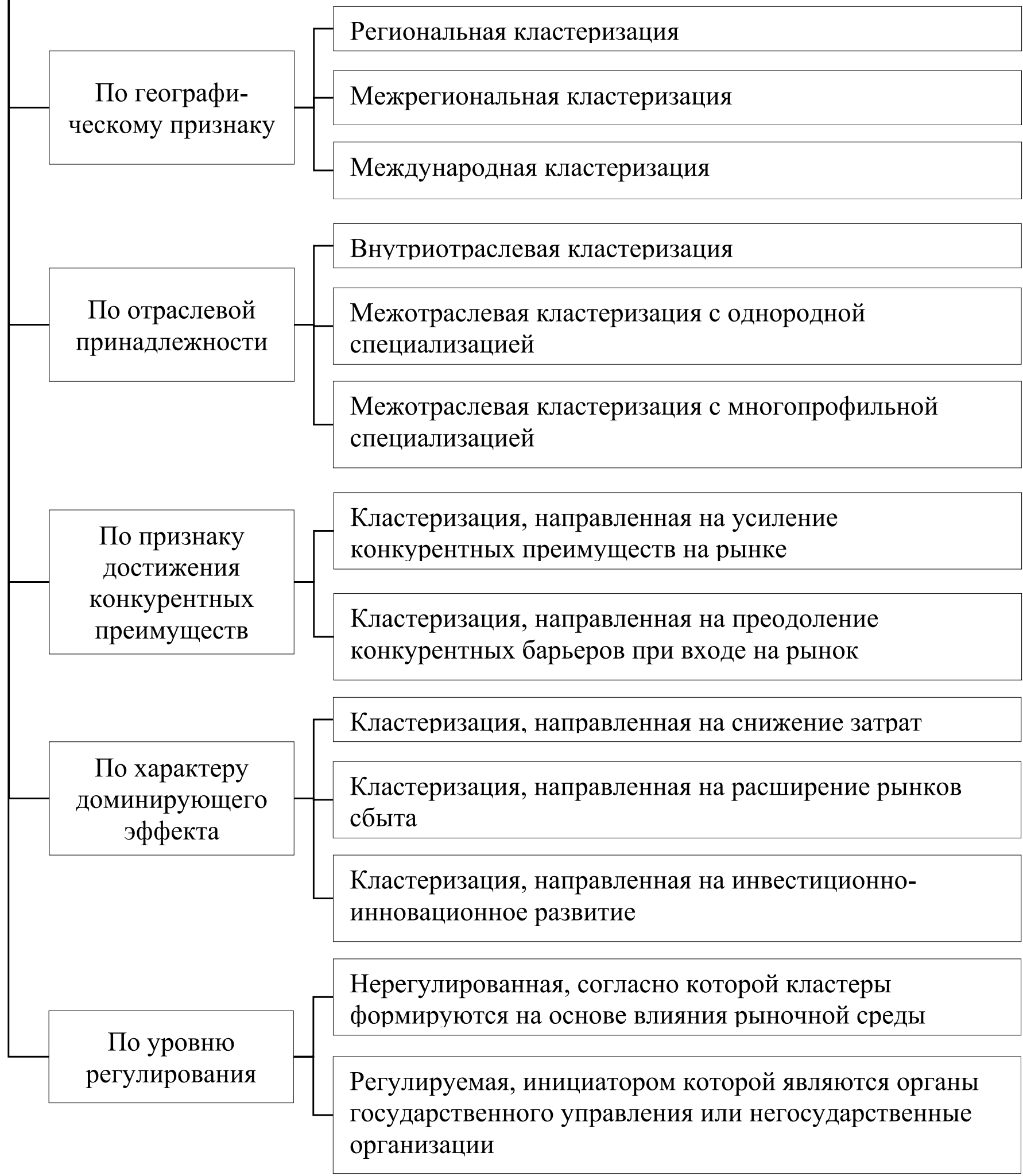

Рис. 2. Кластеризация форм национальной экономики Источник: составлено автором 
на эффекте масштаба производства (при росте объемов производства объем постоянных производственных затрат в расчете на единицу продукции сокращается, в результате чего происходит рост экономического эффекта в работе каждого предприятия кластера). Большинство исследований акцентируют внимание на классификации форм кластеров, однако недостаточно внимания уделяется определению моделей кластеризации, в частности описания практической их реализации на примере опыта различных стран. В связи с этим попробуем сформировать классификацию форм кластеризации экономики исходя из основных детерминант создания кластеров (рис. 2).

По географическому признаку возможными е региональная, межрегиональная и международная формы кластеризации. Региональная форма предусматривает образование кластеров в географических пределах только одного региона.

Сюда можно отнести формирование кластеров в рамках определенных отраслей, которые развиваются в конкретном регионе (туристическая сфера, некоторые отрасли АПК, пищевой и легкой промышленности). Межрегиональная кластеризация характеризуется одновременным формированием кластеров в нескольких регионах страны. Данная форма кластеризации предусматривает объединение предприятий и организаций различных регионов, которые функционируют в рамках одной или смежных отраслей (например, добывающая, металлургическая, химическая, машиностроительная промышленность).

Международная кластеризация присуща для межгосударственных объединений (ЕС, нефть, АСЕАН и т.д.). Для нее характерным является объединение субъектов хозяйствования и некоммерческих структур соответственно к формированию связей на уровне международного делового сотрудничества. Показательным примером является формирование международных кластеров в машиностроительной отрасли, когда из деталей и комплектующих, изготовленных в одной стране, происходит сборка готовой продукции в иной (международные концерны BMW, Audi, Nissan, Тоуота и др.).

По отраслевой принадлежности предлагаем выделять внутриотраслевую кластеризацию, межотраслевую кластеризацию с однородной и многопрофильной специализацией. Внутриотраслевая форма кластеризации характеризуется формированием кластеров в рамках одной отрасли (металлургия, машиностроение, туризм, пищевая промышленность, химическая промышленность). Она очень часто совпадает с региональной формой.
Межотраслевая кластеризация предусматривает объединение предприятий и организаций различных отраслей экономики. При этом используется однородная и многопрофильная специализация. Однородная специализация предполагает объединение в рамках взаимодополняющих отраслей, то есть в рамках одного промышленного комплекса. Отличительным признаком такой формы кластеризации является то, что продукция предприятий определенной отрасли является законченным готовым продуктом (не е сырьем и может свободно реализовываться на рынке), который используется для создания более сложных продуктов других отраслей.

Конкурентный признак форм кластеризации основывается на координации действий предприятий, объединяемых по отношению к конкурентной среде. Кластеризация направлена на усиление конкурентных преимуществ на рынке, предполагает объединение хозяйствующих субъектов с целью оптимизации производственных процессов в рамках треугольника: цена-качество-время. Следствием такой формы кластеризации также может быть процесс монополизации рынка, вытеснению с него экономически слабых предприятий.

Кластеризация, направленная на преодоление конкурентных барьеров при входе на рынок, осуществляется также с целью проникновения на рынки путем диверсификации производства и ассортимента товаров (услуг). Показательным примером является формирование мультибрендовой структуры производства, когда происходит проникновение предприятий на рынок в различных потребительских и ценовых сегментах. Суть данной формы кластеризации заключается в том, что одному предприятию проникнуть одновременно на все сегменты рынка гораздо сложнее (в силу инфраструктурных и технологических особенностей, наличием законодательных антимонопольных ограничений, рыночных ограничений и тому подобное), чем осуществить это отдельным предприятиям, каждое из которых будет занимать свой сегмент. Примером может служить всемирно известный Volkswagen Group - одно из крупнейших предприятий в отрасли автомобилестроения в мире. На сегодняшний день в его состав входят 12 компаний: Volkswagen, Audi, Skoda, Seat, Lamborghini, Bugatti, Bentley, Man, Scania, Volkswagen коммерческие автомобили, Porsche и Ducati. Каждая компания занимает свой сегмент рынка, а также обеспечивается соответствие антимонопольному законодательству.

По характеру доминирующего эффекта автор предлагает выделять формы кластеризации, направленные на: снижение затрат, расширение рынков сбыта, инвестиционно-инновационное развитие. Снижение затрат, согласно результатам теоретического исследования 
научных подходов, связано с эффектом масштаба производства. Поэтому, данная форма кластеризации используется преимущественно в специализированных производствах, которые дополняют друг друга и формируют единый цикл выпуска продукции (например, производство строительных материалов, которое сочетает в себе добычу сырья).

Кластеризация, направленная на инновационно-инвестиционное развитие, предусматривает объединение предприятий и организаций с целью совместного развития науко- и технологоемких производств. Примером может служить всем известная силиконовая долина В США, объединения предприятий аэрокосмической отрасли, нано технологий и генной инженерии.

По уровню регулирования кластеризация может быть регулируемой органами государственного управления или рыночной средой. Первая форма характерна для реализации политики государственного регионального развития и предполагает прежде всего достижение общего социально-экономического эффекта на уровне государства в целом. При этом интересы отдельных участников (предприятий и организаций) могут не учитываться или же их деятельность может носить убыточный характер. Вторая форма кластеризации характерна для частного капитала. Она максимально учитывает интересы всех участников и, согласно законам рынка, оптимизирует процесс создания добавленной стоимости путем их объединения. Экономически слабые участники отсеиваются и долго не функционируют. Вторая форма кластеризации, несмотря на ее высокую экономическую целесообразность, способна приводить к диспропорциям регионального развития, что ставит под угрозу достижение целей социального развития.

\section{Ка^ужская область: к^астерный по $\triangle$ Хо $\triangle$ в автомобилестроении}

Рассматривая автомобильную отрасль, можно выделить несколько регионов, в которых внедрение кластера доказало свою экономическую рентабельность и позволило получить положительный опыт для будущих разработок на новых, еще не разведанных специалистами территориях. В настоящее время уже практически сформировались 3 ключевых автомобильных кластера (по месту концентрации производств конечной продукции) [5]:

1. Приволжский: г. Тольятти/г. Самара; г. Набережные Челны/ОЭЗ «Алабуга»; г. Ульяновск; г. Нижний Новгород;

2. Центральный: г. Москва/г. Калуга; г. Владимир;

3. Северо-западный: г. Санкт-Петербург; г. Великий Новгород/г. Псков.
Одним из наиболее инновационных регионов является Калужская область. Начало строительства производственных мощностей и, в целом, официальный запуск кластера состоялись еще в 2006 году. Фактически формирование межотраслевых кластеров стало основным драйвером развития региона.

С точки зрения кластерной нормативно-правовой базы Российской Федерации объединение автомобильных предприятий Калужской области не относиться ни к одному из двух ключевых направления развития кластеров: инновационные территориальные кластеры Минэкономразвития России или промышленные кластеры Минпромторга России, а, следовательно, не может воспользоваться соответствующими механизмами кластерной поддержки. И чтобы продолжать развитие кластерной политики региона и дать возможность автомобильным предприятиям внутри кластера создавать цепочки кооперации и новые промышленные нововведения, и при этом пользоваться государственной поддержкой правительство Калужской области планирует оформление кластера автомобилестроения в промышленный с включением в Реестр Минпромторга РФ.

По предварительному анализу кластер автомобилестроения Калужской области соответствует всем требованиям, которые предъявляет Минпромторг РФ. В частности, среди них — наличие не менее 10 промышленных предприятий отрасли, одно из которых должно выпускать конечную продукцию; уровень кооперации среди участников должен быть не менее $20 \%$; в числе участников кластера должны действовать не менее 2 образовательных организаций и один объект технологической инфраструктуры [6].

Автомобильные кластеры являются одним из ключевых факторов успеха автомобильной индустрии. Автомобильный кластер калужского региона продемонстрировал это на своем примере. Еще 10 лет назад доля автопрома в валовом региональном продукте равнялась единицам процентов. На данный момент мы наблюдаем огромный скачок, когда доля автопрома в валовом региональном продукте приближается к 50\% (рис. 3).

На сегодняшний день предприятия-участники кластера создают большинство основных компонентов, необходимых для обеспечения деятельности автопрома: двигатели, масла, шины, стекла, электронику - это все те новые компетенции, которые рождались в регионе.

Основная стратегия устойчивого развития Калужского региона основана на таких базовых приоритетах:

1. тройная спираль взаимодействия власти, бизнеса и университетов (образование и научные исследования); 


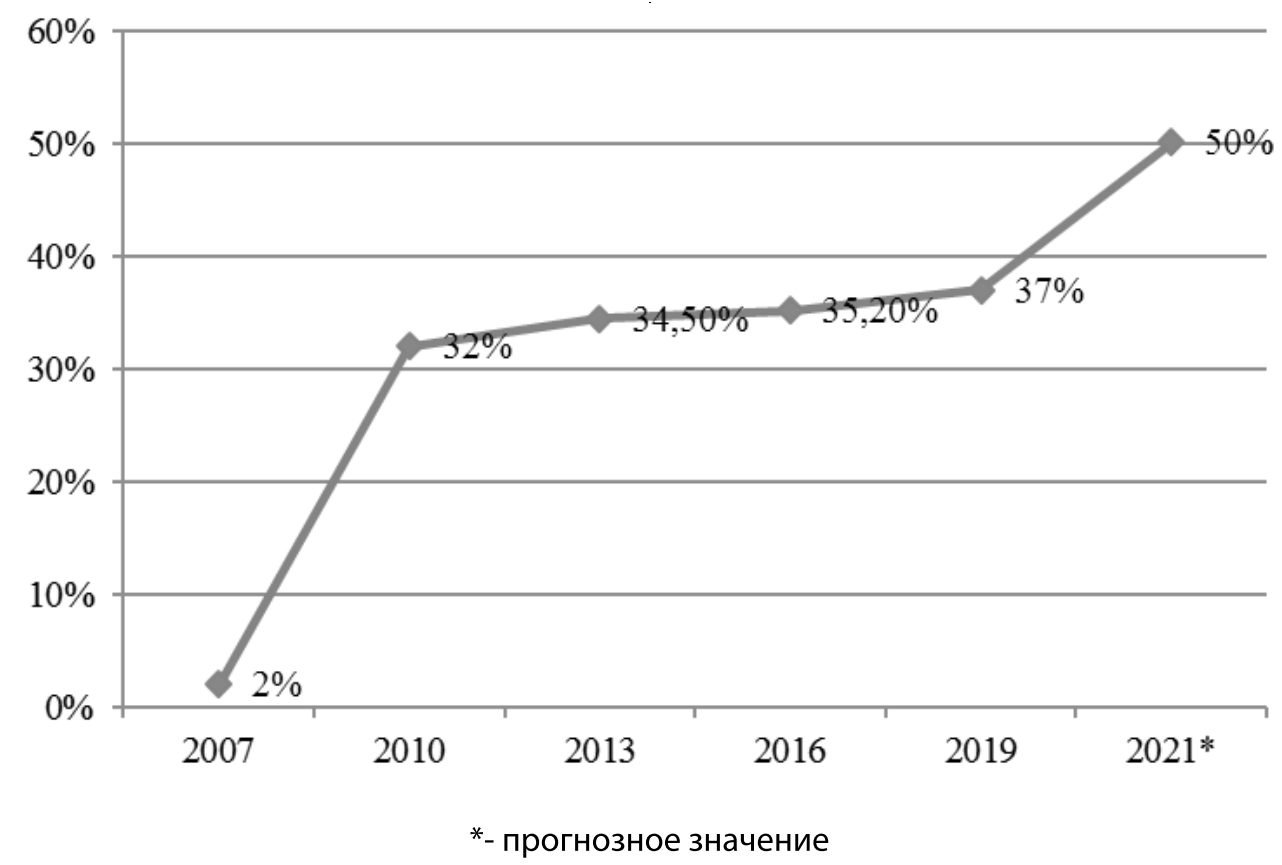

Рис. 3. Доля автопроизводства в промышленном объеме региона по годам [7]

2. кластерное развитие экономики региона;

3. комфортные условия проживания (высокое качество жизни).

Основные инвесторы автомобильного кластера это три ОЕМ-производителя: Volkswagen, PSA Peugeot Citroën \& Mitsubishi Motors и Volvo Trucks. Вслед за ними свои производства на территории региона разместили другие поставщики автокомпонентов, среди которых компании Magna, Continental, Faurecia, Visteon, Gestamp-Северсталь и пр.

Технологическая инфраструктура кластера представлена Калужским лазерным инновационно-технологическим центром, выполняющим функции центра коллективного пользования и оказывающим необходимые технологические услуги предприятиям-участникам кластера автомобилестроения Калужской области. Несмотря на то, что юридически автомобильный кластер калужской области не оформлен, это не препятствует кооперации между его участниками:

1. ООО «ФОЛЬКСВАГЕН КС» поставляет двигатели внутреннего сгорания для комплектации автомобилей «Фольксваген», произведенных в Нижнем Новгороде.

2. ООО «ФУЯО СТЕКЛО РУС» ВЫпУскает автомобильное стекло для компаний автомобильной отрасли «Хёндэ», «Ниссан», «Рено», «Вольво», «Газ».

3. КОМПАНИЯ «АИС АВТОМОТИВ ИНТЕРИОР СИCTEM» (AIS Automotive Interior Systems $\mathrm{GmbH}$ ), работающая на производственных площадях ПАО «Агрегатный завод» в г. Людиново, поставля- ет пластиковые комплектующие для Volkswagen, Mercedes-Benz, BMW, Ford, Toyota.

4. ООО «ПСМА РУС» - стратегический партнер предприятия ООО «НПП «Полипластик» (Саратовская обл.).

5. Ряд предприятий Калужской области производит продукцию для АвтоВАЗа. Сейчас ядро калужского автокластера составляют три предприятия - «Фольксваген Груп Рус», «Пежо-Ситроен Митсубиши Аутомотив» и концерна Volvo. Благодаря запуску заводов этих трех компаний удалось привлечь в область производителей деталей и создать целую инфраструктуру поставок запчастей - сейчас заводы сотрудничают с 60 локальными поставщиками.

Так как калужский автокластер территориально относится к центральному кластеру, но нельзя не обратить внимание строительство и запуск нового автомобильного завода в Московской области. Предприятие концерна Daimler, заложенное в Солнечногорском районе Московской области в июне 2017 года, сегодня официально введено в строй.

Завод работает в рамках специального инвестиционного контракта (СПИКа) с Минпромторгом России. Суть СПИКа в том, что он заключается между российским правительством и инвестором, при этом последний гарантирует вложение денег (не менее 750 миллионов рублей) и создание рабочих мест, а российская сторона обещает ему меры стимулирования деятельности и стабильные условия ведения бизнеса. 
Первым на конвейер встал седан Mercedes E-класса: в Есипово выпускают модификации E200, E200 d и E220 d, как с задним, так и с полным приводом. Все машины в фиксированных комплектациях, так что об индивидуальном заказе речи нет. Через несколько месяцев российскую прописку обретет кроссовер Mercedes GLC (уже в обновленном виде), а к концу года или в начале 2020-го на российский конвейер встали модели GLE и GLS. Хотя в компании и заявляют о высокой гибкости российского завода, начинать производство любимого чиновниками S-класса здесь пока не планируют.

В 2019 году все калужские автосборочные предприятия «Фольксваген», «ПСМА Рус» и «Вольво» заключили СПИК с участием Российской Федерации. Поэтому важным вектором развития кластера видится именно кооперация всех автопромышленных объектов центрального кластера согласно Стратегии развития автомобильной промышленности Российской Федерации на период до 2020 г. [8].

\section{Выво $\triangle \mathrm{bl}$}

Таким образом, приведенные выше формы кластеризации экономики, с выраженными в той или иной степени, для всех процессов кластерообразования едины. При этом важно подчеркнуть, что формирование кластеров происходит в реальной жизни одновременно в не- скольких формах. Каждая форма выделяет лишь определенные особенности процесса формирования кластера. Поэтому многогранность развития кластеров определяет разнообразие форм кластеризации экономики.

Основными детерминантами кластеризации экономики определены следующие: необходимость достижения конкурентных преимуществ; наличие снижения издержек (положительный эффект масштаба); рост гибкости и мобильности работы предприятий; рост доступности инвестиций, технологий, рынков; научно-технический прогресс; инновационный развитие.

Предложено учитывать такие детерминанты как социальная значимость и политическая целесообразность в процессе кластеризации экономики. Исходя из обоснования детерминант развития кластеров, разработана и предложена классификация форм кластеризации экономики, в результате чего удалось выделить следующие ее признаки: география, отраслевая принадлежность, достижение конкурентных преимуществ, характер доминирующего эффекта, уровень регулирования.

На примере Калужского региона видно, что локализация производства с формированием пула отечественных поставщиков вокруг предприятия с иностранными инвестициями - это эффективный инструмент кластерной экономики.

\section{ЛИТЕРАТУРА}

1. Адамова К. 3. Кластеры: Понятия, условия возникновения и функционирования // Вестник Саратовского университета. 2008. — № 3 (34). - С. 129-135.

2. Дуненкова Е. Н. Методологические основы управления формированием и развитием инфраструктуры региональной инновационной системы [Текст]: монография / Дуненкова Е. Н.; Государственный университет управления.— М.: ГуУ, 2013.— 141 с.

3. Палкина М. В. Формирование инновационной системы управления развитием промышленного комплекса региона: Автореферат дисс. на соискание ученой степени д.э.н.: 08.00.05 / М. В. Палкина.—Ижевск, 2010.

4. Шарко Е. Р. Подходы и методы выбора показателей BSC для предприятия с учетом специфики бизнеса // Международное научное издание Современные фундаментальные и прикладные исследования. — 2014. — № 2(13). — C. 147-152. URL: https://elibrary.ru/item.asp?id=21638836.

5. Федеральный закон от 31 декабря 2014 г. N488-Ф3 «0 промышленной политике в Российской Федерации».

6. Калужский кластер автомобилестроения может стать промышленным. URL: https://regnum.ru/news/economy/2609074.html.

7. Вестник Министерства экономического развития Калужской области № 6, 2019 г. URL: https://arrko.ru/uploads/heralds/180/ad1e6dc003d212e6.pdf.

8. Методические рекомендации по реализации кластерной политики в северных субъектах Российской Федерации. URL: https://www.tpprf.ru. 